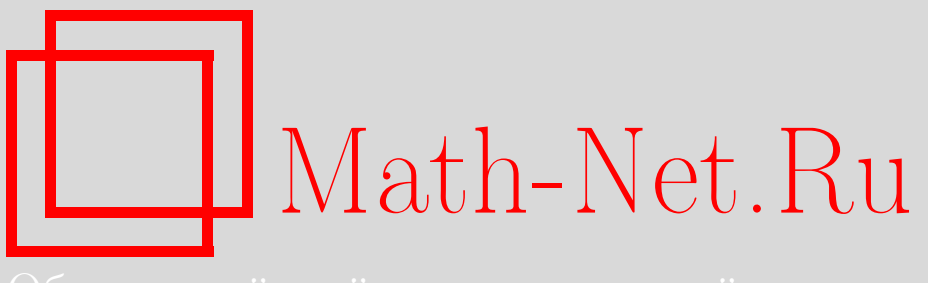

Общероссийский математический портал

Р. А. Минлос, Р. Л. Добрушин - один из основоположников современной математической физики, УМН, 1997, том 52, выпуск 2, 13-18

DOI: https://doi.org/10.4213/rm1583 
Использование Общероссийского математического портала Math-Net.Ru подразумевает, что вы прочитали и согласны с пользовательским соглашением

http://www.mathnet.ru/rus/agreement

Параметры загрузки:

IP : 54.197 .130 .99

26 апреля 2023 г., 15:33:10

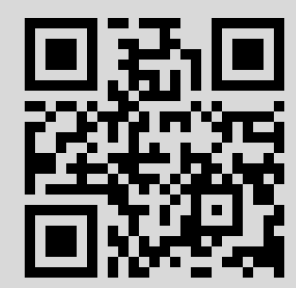




\section{Р. Л. ДОБРУШИН - ОДИН ИЗ ОСНОВОПОЛОЖНИКОВ СОВРЕМЕННОЙ МАТЕМАТИЧЕСКОЙ ФИЗИКИ}

\section{Р.А. Минлос}

Что такое математическая физика? Р. Л. Добрушин как-то рассказал мне, что на вопрос своего знакомого (не математика) о том, чем он - Добрушин - занимается, Роланд Львович ответил: "Преврашаю прикладную математику в чистую”. Эта шутка, мне кажется, очень метко определяет суть математической физики. Это, конечно же, математика, черпаюшая свои задачи в физике. Разумеется, людям, занимающимся математической физикой, приходится порой серьезно углубляться в самую физику и даже в тот жаргон, на котором изъясняются физики, но это лишш черновая часть их работы. Окончательньй продукт состоит из теорем и конструкций, образующих новые математические теории или развиваюших уже сушествуюшие. И как мы увидим, 
деятельность Р. Л. Добрушина в математической физике очень точно иллюстрирует эту схему. Более того, он был одним из пионеров именно такого понимания математической физики.

В начале 60-х годов Р.Л. Добрушин, занимавшийся в то время теорией информации, ощутил некоторую исчерпанность этой темы и даже, более того, исчерпанность общепринятых в то время тем теории вероятностей. Он начал искать новые задачи в вероятностном духе, связанные с физикой. Счастливым образом, такая проблема нашлась: математическое обоснование равновесной статистической механики. Р.Л. Добрушин совместно с автором этой статьи (а затем и с Я. Г. Синаем) начинает вести на механико-математическом факультете МГУ семинар по изучению основ статистической физики. Это семинар открылся осенњю 1962 года и просуществовал до весны 1994 года. Сразу следует отметить, что этот семинар уже через несколько лет завоевал мировую известность; здесь были выработаны наиболее сушественные концепщии современной математической статистической физики и было решено несколько важных задач, во многом определивших ее нынешний характер. Кроме того, на этом семинаре воспитано по крайней мере два поколения ученых, активно работающих сейчас в математической физике. Почти вся деятельность Р. Л. Добрушина по статистической физике была связана с этим семинаром.

Роланду Львовичу принадлежит огромное число результатов в этой области. Их полное - хотя и краткое - описание содержится в большой статье, посвященной анализу всего математического творчества Р. Л. Добрушина [1]. В этой же статье приведен и полный список опубликованных им научных работ.

В этом же очерке мне хочется вкратце остановиться на четырех наиболее важных и ярких темах из математической статистической физики, изучавшихся Роландом Львовичем.

\section{1. Фазовые переходы}

Фазовые переходы являются одним из самых поразительных явлений в статистической физике, и их обнаружение, описание и классификация составляют ее центральную проблему. Первые строгие математические работы по теории фазовых переходов появились в середине 60-х годов, и одна из них принадлежит Р. Л. Добрушину [2]. Эта глубокая работа, ставшая впоследствии широко известной, посвяшена доказательству сушествования фазового перехода 1-го рода в двумерной и трехмерной ферромагнитных моделях Изинга при низких температурах и нулевом магнитном поле. Следующий результат Добрушина касался сушествования фазового перехода в системах со смешанным антиферромагнитным и ферромагнитным взаимодействиями, в котором, однако, преобладает последнее [3]. В случае же чистого антиферромагнетика Изинга две различные фазы существуют при низких температурах в целом диапазоне значений магнитного поля. Этот результат содержится в работе Р. Л. Добрушина [4].

В дальнейшем Р. Л. Добрушин не раз обрашался к проблеме фазовых переходов. Укажем, во-первых, работу [5] (совместную с В. Герциком), в которой установлено наличие фазовых переходов для некоторого класса решетчатых систем (с конечным множеством значений спина) с взаимодействием спинов, удаленных не более, чем на два шага решетки. Сушественным для этих систем является наличие в них некоторых симметрий, "нарушаемых" при фазовых переходах: имеется несколько гиббсовских 
распределений (“фаз”), каждое из которых уже лишено части симметрий. В этой работе было введено важное понятие “основного состояния" системы (т.е. бесконечной конфигурации спинов на решетке с "наименьшей энергией”), а также явно сформулировано так называемое “условие Пайерлса”. Эти понятия и концепции оказались ключевьми в более общей теории фазовых переходов, построенной несколькими годами позже С. А. Пироговым и Я. Г. Синаем [6]. Другой важный результат Р. Л. Добрушина [7], [8] - открытие им специального вида неоднородных фаз (это явление в англоязычной математической литературе обозначается словом "roughening" (огрубление, отвердение)). Такие фазы появляются, в частности, в трехмерной ферромагнитной модели Изинга при низких температурах и нулевом магнитном поле и состоят из двух однородных $(+)$ и $(-)$ фаз, сосушествуюших в пространстве так, что каждая из них заполняет свое полупространство, а граница между фазами представляет собой “флуктуируюшую” плоскость. В случае антиферромагнитного взаимодействия также возникает "roughening", но уже в целом диапазоне значений магнитного поля. В работах [9] и [10] было доказано (разными способами) существование фазового перехода для взаимодействия с одним глобальным и одним локальньм минимумами (достаточно большой “ширины”). Это многих поразило, так как считалось, что для взаимодействий с единственным глобальным минимумом фазовьй переход не возникает.

\section{2. Гиббсовские случайные поля (ДЛР-определение и все об этом)}

К конщу 60-х годов после работ Д. Рюэля, Р. А. Минлоса, а также Р. А. Минлоса и Я. Г. Синая стала ясна природа того предельного объекта, который описывает статфизическую систему после совершения термодинамического предельного перехода: это пространство $\Omega$ бесконечных конфигураций системы с некоторым распределением вероятностей на $\Omega$, являющимся в некотором смысле “предельньм” для конечных гиббсовских распределений. При этом в некоторых случаях такое предельное распределение единственно, а в других случаях возникает несколько таких распределений (фаз). Появляется вопрос - каково внутреннее свойство этих распределений, связьвающее их с потенциалом взаимодействия системы? Отвечая на этот вопрос, Р. Л. Добрушин, а также независимо от него О. Ланфорд и Д. Рюэль, пришли к общему определению бесконечного гиббсовского поля (это определение обозначается с тех пор аббревиатурой ДЛР). Согласно этому определению гиббсовское поле на $\Omega$ обладает тем свойством, что для любого конечного подмножества $\Lambda$ решетки (или пространства) и любой фиксированной конфигурации $\bar{\sigma}$ спинов вне этого подмножества условное распределение вероятностей для конфигураций спинов внутри $\Lambda$ задается известной гиббсовской формулой, в которой энергия конфигурации спинов $\sigma$ в $\Lambda$ включает энергию взаимодействия $\sigma$ с $\bar{\sigma}$.

Р. Л. Добрушин в большом цикле работ [11]-[15] исследовал это понятие и многие его аспекты (сушествование гиббсовских полей при заданном потенциале взаимодействия, критерии единственности такого поля, свойства убьвания его корреляций, аналитическую зависимость от параметров и т. д.). Наиболее трудная и глубокая тема в этих исследованиях, занимавшая Р. Л. Добрушина многие годы, - нахождение критериев единственности гиббсовских полей на дискретном множестве (скажем, на решетке $\mathbb{Z}^{\nu}$ ) для заданного взаимодействия. 


\section{3. Марковские процессы с локальным взаимодействием}

В конце 60-х и начале 70-х годов Р.Л. Добрушин под влиянием работ групш И. И. Пятецкого-Шапиро в Московском университете (О.Н. Ставская, Н.Б. Васильев, Л.Н. Вассерштейн, А. Л. Тоом, А. М. Леонтович и др.), в которых изучались некоторые модели биологического роста, ввел общее понятие марковского процесса с локальным взаимодействием [16], [17]. Это процесс с бесконечным числом компонент, помеченных точками некоторого графа $G$ (например, решетки $\mathbb{Z}^{\nu}$ ), такой, что условная вероятность изменения компоненты в точке $t \in G$ зависит от значений компонент только в соседних точках графа (более общо - в точках из некоторой конечной окрестности $t$ ). Кроме того, что Р. Л. Добрушин заложил основы теории таких процессов, он применил их к гиббсовским полям, построив для каждого потенциала взаимодействия марковскую полугруппу, для которой все гиббсовские поля на графе $G$ служат ее стационарными распределениями. K настоящему времени теория таких процессов обросла значительной литературой и превратилась в самостоятельную науку, обильную результатами, методами и приложениями.

\section{4. Конструкция Вульфа и теория больших уклонений в двухфазной области}

Несколько последних лет своей жизни Р. Л. Добрушин вместе с сотрудниками занимался подробным изучением структуры конфигураций в модели Изинга, типичных относительно малого ансамбля Гиббса при низких температурах $T$. Результатом этих занятий явилась монография [19], написанная Р. Л. Добрушиньм, Р. Котецким и С. Б. Шлосманом. Структура типичных конфигураций для чистой (скажем, (+)-фазы) была исследована давно в работах Р. А. Минлоса и Я.Г. Синая (см., например, [20]). А именно, для распределения Гиббса с (+)-граничными условиями в квадрате $N \times N \subset \mathbb{Z}^{2}$ с вероятностью, близкой к единице (при достаточно большом $N$ ), плотность отрицательных "спинов" в каждой конфигурации близка к некоторому значению $\rho_{-}(T)<\frac{1}{2}$, а сами эти спины собираются в редко расположенные "микро-капельки", размер которых не превосходит $O(\ln N)$. Спрашивается, каков будет вид конфигурации, типичной относительно условного распределения в (+)-фазе, при условии, что плотность $\rho$ отрищательных спинов фиксирована, причем $\rho_{-}(T)<\rho<\frac{1}{2}$. Как было показано в упомянутой работе Р. А. Минлоса и Я.Г. Синая, с вероятностью, близкой к единице, каждая конфигурация содержит единственную макрокаплю $\Gamma$ (размера $\sim N$ ), состоящую из (-)-фазы и “плаваюшую" внутри (+)-фазы (площадь $|\Gamma|$ этой "капли" однозначно определяется значением $\rho$ так, что суммарное число отрицательных спинов в обоих частях - в "капле" и вне нее - равно $N^{2} \rho$ ). Р. Л. Добрушин с сотрудниками детально исследовали типичную форму этой "капли". Оказалось, что "капля" близка к овалу $W N$, где $W$ - некоторая плоская кривая, описываемая как решение определенной вариационной геометрической задачи. Эта кривая называется кривой Вульфа (в честь казанского профессора Вульфа, впервые построившего ее в давней работе 1900 г.). Вульф занимался той же задачей, только применительно к фазам в непрерьвном вешестве, и исходил, конечно, из чисто феноменологических представлений. Самым удивительным в результате Добрушина, Котецкого и Шлосмана оказалось то, что эта феноменологическая тонкая конструкция может 
быть строго обоснована (хотя бы в рамках модели Изинга) с помощью исследования явлений микроуровня.

Дальнейшее развитие все эти идеи получили в работе [21]. В этой работе изучалась картина типичных конфигураций для $d$-мерной модели Изинга, когда $\rho$ лишь немного отклоняется от $\rho_{-}(T)$. При этом в диапазоне значений

$$
\rho_{-}(T)<\rho<\rho_{-}(T)+O\left[\left(\left|V_{N}\right|\right)^{(d-1) / d}\right]
$$

$\left(V_{N}-\right.$ куб со стороной $\left.N\right)$ большой капли еще нет, но когда $\rho$ переходит через этот порог, появляется одна большая капля размера $O\left(N^{\alpha}\right), \alpha>0$. Эти результаты тесно связаны с вероятностями больших уклонений для намагниченности (т.е. суммарного спина системы) в каждой из фаз. В случае, когда намагниченность $M$ в (+)-фазе больше средней намагниченности (а это происходит из-за уменшшения числа отрицательных спинов), вероятности больших уклонений $M$ ведут себя “классически”. При значениях намагниченности, меньших среднего значения, вид вероятностей больших уклонений из-за появления “капли” уже отличается от классических выражений.

Кроме перечисленных мною основных тем, Р. Л. Добрушин занимался и многими другими вещами из статистической физики (изучение предельных термодинамических функций, изучение гауссовских полей с гиббсовской точки зрения, исследование класса так назьваемых "вполне аналитических" гиббсовских полей, подробное исследование одномерных гиббсовских полей и т. д.; см. подробнее в [1]).

Bсе эти работы, написанные с тщательностью и полнотой и свидетельствующие о необыкновенной научной плодовитости Роланда Львовича, увы, не могут дать полного представления о живом потоке его мыслей и творческих озарений. Мне посчастливилось долгие годы наблюдать талант Р. Л. Добрушина в его непосредственных проявлениях (в совместной работе, на семинарах, в частых научных беседах с ним). Наиболее яркой чертой в нем была необыкновенно глубокая интуиция и богатство ассоциативных связей - он сразу умел проникнуть в суть проблемы и осветить ее с неожиданной стороны. Другая его особенность - удивительная ясность ума - все, что он говорил, отличалось последовательностью и логичностью. Наконец, у меня всегда вызьвали восхишение его неутомимость и умение работать и размышлять в любых условиях. Например, в последние месяцы своей жизни, будучи тяжело больным, он продолжал работать с той же интенсивностью, что и прежде. Он всегда был очень требовательным к своим статьям, часто переписьвал их по нескольку раз; некоторые работы, над которыми он долго трудился, но видимо чем-то его не удовлетворившие, он так и не опубликовал. Все, что он сделал в науке и в математической физике, в частности, отличается фундаментальной завершенностью; и в этом, я думаю, залог дальнейшего развития его начинаний и идей.

\section{СПИСОК ЛИТЕРАТУРЫ}

[1] Бассалыго Л.А., Малышев В.А., Минлос Р.А., Овсиевич И.А., Пинскер М. С., Прелов В. В., Сухов Ю. М., Шлосман С. Б. Памяти Роланда Львовича Добрушина // Проблемы передачи информации. 1996. Т. 32. № 3.

[2] Добрушин Р. Л. Существование фазового перехода в двумерной и трехмерной моделях Изинга // Теория вероятн. и ее примен. 1965. Т. 10. №2 2. С. 209-230. 
[3] Dobrushin R. L. Existence of phase transition in models in lattice gas // Proc. of the Fifth Berkeley Symp. on Math. Statist. and Probab. V. 3. Univ. of California Press: Berkeley CA, 1966. P. 73-87.

[4] Добрушин Р.Л. Задача единственности гиббсовского случайного поля и проблема фазовых переходов // Функц. анализ и его прилож. 1968. Т. 2. № 2. С. 44-57.

[5] Герцик В., Добрушин Р. Л. Гиббсовские состояния в решетчатой модели с взаимодействием на 2 шага // Функц. анализ и его прилож. 1974. Т. 8. № 3. С. 12-25.

[6] Синай Я. Г. Теория фазовых переходов (строгие резултаты). М.: Наука, 1980.

[7] Добрушин Р. Л. Гиббсовские состояния, описывающие сосуществование фаз в трехмерной модели Изинга // Теория вероятн. и ее примен. 1972. Т. 17. № 4. С. 619-639.

[8] Добрушин Р. Л. Исследование гиббсовских состояний для трехмерных решетчатых систем // Теория вероятн. и ее примен. 1973. Т. 18. № 2. С. 261-279.

[9] Dobrushin R.L., Shlosman S. Phases corresponding to minima of the local energy // Selecta Math. Soviet. 1981. V. 1. № 4. P. 317-338.

[10] Dobrushin R. L., Zahradnik M. Phase diagrams for continuous-spin models. An extention of the Pirogov-Sinai theory // Math. Problems of Statist. Mech. and Dynam. Dordrecht: Reidel, 1986. P. 1-124.

[11] Добрушин Р. Л. Описание случайного поля с помощью условных вероятностей и условия его регулярности // Теория вероятн. и ее примен. 1968. Т. 13. № 2. С. 201-229.

[12] Добрушин Р. Л. Гиббсовские случайные поля для решетчатых систем с парными взаимодействиями // Функц. анализ и его прилож. 1968. Т. 2. № 2. С. 31-43.

[13] Добрушин Р. Л . Гиббсовские поля. Общий случай // Функц. анализ и его прилож. 1969. Т. 3. №1. С. 27-35.

[14] Добрушин Р.Л.Гиббсовские случайные поля для частиц без твердой середины // ТМФ. 1970. Т. 4. №1. С. 101-118.

[15] Добрушин Р. Л. Задание системы случайных величин с помощью условных распределений // Теория вероятн. и ее примен. 1970. Т. 15. № 3. С. 469-497.

[16] Добрушин Р. Л. Марковские процессы с болшшим числом локально взаимодействующих компонент: существование предельных процессов и их эргодичность // Пробл. передачи информ. 1971. Т. 7. № 2. С. 70-87.

[17] Добрушин Р. Л. Марковские процессы со многими локально взаимодействующими компонентами - обратимый случай и некоторые обобщения // Пробл. передачи информ. 1971. Т. 7. № 3. С. $57-66$.

[18] Лигетт Т. Марковские процессы с локальным взаимодействием. М.: Мир, 1989.

[19] Dobrushin R.L., Cotecky R., Shlosman S. Wulf construction: A Global Shape From Local Interaction. Providence RI: Amer. Math. Soc., 1992.

[20] Минлос Р. А., Синай Я. Г. Явление "разделения фаз" при низких температурах в некоторых решетчатых моделях газа. I // Матем. сб. 1967. Т. 73. №3. С. 335-395.

[21] Dobrushin R. L., Shlosman S. Large and moderate deviations in the Ising model // Probability Contributions to Statistical Mechanics / ed. R.L. Dobrushin. Providence RI: Amer. Math. Soc., 1994. P. 91-219. 